\title{
Role of Lactic Acid Bacteria Phospho- $\beta$-Glucosidases during the Fermentation of Cereal by-Products
}

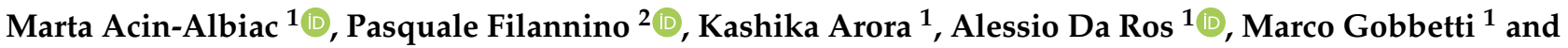 \\ Raffaella Di Cagno ${ }^{1, *}$
}

1 Faculty of Science and Technology, Libera Universitá di Bolzano, 39100 Bolzano, Italy; marta.AcinAlbiac@natec.unibz.it (M.A.-A.); kashika.arora@natec.unibz.it (K.A.); alessio.daros@natec.unibz.it (A.D.R.); marco.gobbetti@unibz.it (M.G.)

2 Department of Soil, Plant and Food Science, University of Bari Aldo Moro, 70126 Bari, Italy; pasquale.filannino1@uniba.it

* Correspondence: raffaella.dicagno@unibz.it; Tel.: +39-0471-017-216

Citation: Acin-Albiac, M.; Filannino, P.; Arora, K.; Da Ros, A.; Gobbetti, M.; Di Cagno, R. Role of Lactic Acid Bacteria Phospho- $\beta$-Glucosidases during the Fermentation of Cereal by-Products. Foods 2021, 10, 97. https://doi.org/10.3390/foods10010097

Received: 29 November 2020 Accepted: 29 December 2020 Published: 5 January 2021

Publisher's Note: MDPI stays neutral with regard to jurisdictional clai$\mathrm{ms}$ in published maps and institutional affiliations.

Copyright: (C) 2021 by the authors. Licensee MDPI, Basel, Switzerland. This article is an open access article distributed under the terms and conditions of the Creative Commons Attribution (CC BY) license (https:// creativecommons.org/licenses/by/ $4.0 /)$.

\begin{abstract}
Bioprocessing using lactic acid bacteria (LAB) is a powerful means to exploit plant-derived by-products as a food ingredient. LAB have the capability to metabolize a large variety of carbohydrates, but such metabolism only relies on few metabolic routes, conferring on them a high fermentation potential. One example of these pathways is that involving phospho- $\beta$-glucosidase genes, which are present in high redundancy within LAB genomes. This enzymatic activity undertakes an ambivalent role during fermentation of plant-based foods related to the release of a wide range of phenolic compounds, from their $\beta$-D-glycosylated precursors and the degradation of $\beta$-glucopyranosyl derived carbohydrates. We proposed a novel phenomic approach to characterize the metabolism drift of Lactiplantibacillus plantarum and Leuconostoc pseudomesenteroides caused by a lignocellulosic by-product, such as the brewers' spent grain (BSG), in contrast to Rich De Man, Rogosa and Sharpe (MRS) broth. We observed an increased metabolic activity for gentiobiose, cellobiose and $\beta$-glucoside conjugates of phenolic compounds during BSG fermentation. Gene expression analysis confirmed the importance of cellobiose metabolism while a release of lignin-derived aglycones was found during BSG fermentation. We provided a comprehensive view of the important role exerted by LAB 6-phospho- $\beta$-glucosidases as well the major metabolic routes undertaken during plant-based fermentations. Further challenges will consider a controlled characterization of $p b g$ gene expression correlated to the metabolism of $\beta$-glucosides with different aglycone moieties.
\end{abstract}

Keywords: phospho-beta-glucosidases; cereal by-products; brewers' spent grain; lactic acid bacteria metabolism

\section{Introduction}

Being widespread in various plant and animal ecological niches, lactic acid bacteria (LAB) metabolism is inevitably linked to human nutrition and food bioprocessing, due to their positive impact on sensory and dietary properties of fermented foods [1]. Plant matrices encompass a wide range of health-promoting substrates (e.g., antioxidants, phenolics, fatty acids and dietary fibers). Bioprocessing of a wide range of plant-derived by-products containing a plethora of nutrients is being revealed as a powerful way to exploit and reintroduce vegetable and cereal by-products into the food chain by enhancing their technological and nutritional properties [2].

LAB have the capability to metabolize a large variety of carbohydrates, which in turn enabled their colonization to numerous plant ecosystems and favored the acquisition of genes through horizontal gene transfer (HGT), encoding for specific carbohydrate metabolism and transport [3]. Nonetheless, the efficacy of overall carbohydrate metabolism by LAB relies only on few metabolic routes, strengthening them with an enormous fermentation potential [4]. $\beta$-D-glucosidase activity represents an example, which undertakes 
an ambivalent role during fermentation of plant-based foods related to the release of a wide range of plant secondary metabolites, such as phenolic compounds, from their $\beta$-D-glycosylated precursors and the degradation of $\beta$-glucopyranosyl-derived carbohydrates [5]. In addition, $\beta$-D-glucosidase activity has been positively associated with the flavor of fermented foods by removing undesired bitter compounds and further release of aroma related compounds [6,7]. Encoding genes for this enzymatic activity are widespread among LAB and, more particularly, phospho- $\beta$-glucosidases related genes are found in high redundancy within their genomes [8]. Phospho- $\beta$-glucosidases catalyze the degradation of phosphorylated glucosides and fibre-related disaccharides, such as cellobiose and gentiobiose, which are activated through the phosphoenolpyruvate (PEP)dependent carbohydrate phosphotransferase systems (PEP-PTS). This system is more commonly found in obligatory and facultative anaerobes and requires specific cellobiose or generic $\beta$-glucosides PTS, which seems to be the substrate-specific part of the catabolic cascade $[5,9]$. The unexplored potentiality of phospho- $\beta$-glucosidase activities and overall carbohydrate metabolism should deserve more attention during the selection of starters for the valorisation of cereal by-products.

Brewers' spent grain (BSG), the most abundant by-product generated in the beerbrewing process, represents an example of valuable raw material and source of health promoting compounds $[10,11]$. BSG is a current challenge within cereal by-products valorisation due to the complexity of its indigestible polymers (e.g., hemicellulose fraction) and anti-nutritional factors (e.g., polyphenols) [12].

In this study, we proposed a phenomic screening on the carbohydrate metabolism fluctuations of Lactiplantibacillus plantarum and Leuconostoc pseudomesenteroides when exposed to a high phenolic and rich-fibre plant matrix, using BSG as model system. The capability of L. plantarum and Leuconostoc species to grow on similar substrates was previously reported $[2,12,13]$. To the best of our knowledge, only few studies investigated in depth the phospho- $\beta$-glucosidase activity within the overall metabolic strategy undertaken by lactic acid bacteria during fermentation of lignocellulosic substrates [14]. Consequently, this study aims to provide an in vivo phenome assessment of how strains of L. plantarum and Leuc. pseudomesenteroides shape their metabolism under a BSG ecosystem. Phenotype switching was further complemented and validated through differential gene expression involved in the adopted metabolic strategies mainly related to phospho- $\beta$-activities.

\section{Materials and Methods}

\subsection{Microbial and Biochemical Characterization of Raw-BSG}

The company Senson-Viking Malt (Helsinki, Finland) kindly supplied Finnish (FL) brewers' spent grain (BSG). Chemical composition of the dried FL-BSG as provided by the manufacturer was as follows: $19.8 \%$ proteins, $2.9 \%$ ash, $55.3 \%$ dietary fibers and $9.4 \%$ carbohydrates. Dry matter content of the BSG was 25.32\% (American Associations of Cereal Chemists approved method 44-15.02). Ten grams of FL-BSG sample was suspended in $90 \mathrm{~mL}$ of sterile sodium chloride $(0.9 \%, w / v)$ solution and homogenized in a Bag Mixer 400P (Interscience, St Nom, France) at room temperature. Presumptive lactic acid bacteria were determined on Rich De Man, Rogosa and Sharpe medium (MRS, Oxoid, Dublin, Ireland) supplemented with cycloheximide $(0.1 \mathrm{~g} / \mathrm{L})$, at $30^{\circ} \mathrm{C}$ for $48 \mathrm{~h}$ under anaerobiosis. Total Enterobacteriaceae were enumerated on Violet Red Bile Dextrose Agar (VRBDA, Oxoid, Dublin, Ireland) at $37^{\circ} \mathrm{C}$ for $24 \mathrm{~h}$, total mesophilic bacteria on Plate Count Agar (PCA, Oxoid, Dublin, Ireland) at $30^{\circ} \mathrm{C}$ for $48 \mathrm{~h}$, and moulds on Potato Dextrose Agar (PDA, Oxoid, Dublin, Ireland) at $32-35^{\circ} \mathrm{C}$ for $48 \mathrm{~h}$.

Yeast cell number was estimated on Malt Extract Agar (MEA, Oxoid, Dublin, Ireland), supplemented with chloramphenicol $(0.1 \mathrm{~g} / \mathrm{L})$ at $30^{\circ} \mathrm{C}$ for $48 \mathrm{~h}$, acetic acid bacteria on Acetobacter Agar (Himedia, Bengaluru, India) supplemented with mannitol at $37^{\circ} \mathrm{C}$ for 24 h. Staphylococcus and Micrococcaceae on Mannitol Salt Agar (MSA, Biolife, Milan, Italia) at $37^{\circ} \mathrm{C}$ for $24 \mathrm{~h}$. Coliforms on Lauryl Sulfate Broth (Sigma-Aldrich, Steinheim, Germany) at $35{ }^{\circ} \mathrm{C}$ for $18 \mathrm{~h}$, Pseudomonas and Aeromonas on GSP Agar (Sigma-Aldrich, 
Steinheim, Germany), supplemented with Penicillin G (60 mg/L) at $28^{\circ} \mathrm{C}$ for $24 \mathrm{~h}$, and enterococci on Enterococcus Differential Agar Base (TITG Agar Base, Himedia, Bengaluru, India), supplemented with TTC solution $1 \%$ (FD057, Himedia, Bengaluru, India) at $37^{\circ} \mathrm{C}$ for $18 \mathrm{~h}$. Total anaerobes and facultative anaerobes on Thioglycollate Agar (TG Agar, Biolife) at $30^{\circ} \mathrm{C}$ for $72 \mathrm{~h}$ under anaerobiosis and on Tryptic Soy Broth (Biolife) at $30{ }^{\circ} \mathrm{C}$ for $24 \mathrm{~h}$ under anaerobiosis, respectively. The results were expressed as colony forming units per one gram of BSG $(\mathrm{CFU} / \mathrm{mL})$.

Mycotoxins (aflatoxins, fumonisin and zearalenone) were analyzed via TLC (thin layer chromatography) as described in the Official Methods of Analysis (AOAC). Fumonisin B1 was assessed through high-performance liquid chromatography-mass spectrometry (HPLC-MS). The results were expressed as micrograms of mycotoxin per one kilogram of BSG.

The mineral content of FL-BSG (calcium, iron, magnesium, manganese, potassium, and sodium) was analyzed through ICP-MS (inductively coupled plasma mass spectrometry) with MI 2385 rev February 2018 method. The results were expressed as milligrams of minerals per one hundred grams of BSG.

\subsection{Preparation of Finnish Brewers' Spent Grain (FL-BSG)-Based Medium}

FL-BSG medium was chosen as model system representative of BSG ecosystem. FLBSG was grinned by a laboratory mill Ika-Werke M20 (GMBH, and Co. KG, Staufen, Germany). Briefly, FL-BSG medium was obtained through a multi-step sequential process. One-hundred grams of FL-BSG were homogenized with $40 \%$ of distilled water, incubated for $18 \mathrm{~h}$ at $25{ }^{\circ} \mathrm{C}$ under stirring conditions (100 rpm), centrifuged $(10,000 \times g$ for $20 \mathrm{~min}$ at $4{ }^{\circ} \mathrm{C}$ ), sterilized by filtration on $0.22 \mu \mathrm{m}$ membrane filters (Millipore, MO, USA), and stored at $-20{ }^{\circ} \mathrm{C}$ before use. MRS medium (Oxoid, Dublin, Ireland) was used as the control. The main chemical composition of FL-BSG medium is shown in Table S1 in the Supplementary Material.

\subsection{Microorganisms and Growth Condition}

Lactiplantibacillus plantarum PU1 obtained from the Culture Collection of the Department of Soil, Plant and Food Science of the University of Bari Aldo Moro (Bari, Italy) and Leuconostoc pseudomesenteroides DSM 20193 obtained from the Leibniz Institute DSMZ (Braunschweig, Germany) were used in this study. These strains were previously characterized for pro-technology (e.g., acidifying and growth capacity) and functional features (e.g., L. plantarum PU1 for the ability to increase the antioxidant activity during BSG fermentation and Leuc. pseudomesenteroides DSM 20193 to synthetize dextran in different food substrates) [2,15]. The aptitude of L. plantarum PU1and Leuc. pseudomesenteroides DSM 20193 to ferment BSG was also verified preliminarily [2,12]. Cultures were maintained as stocks in $15 \%(v / v)$ glycerol at $-80{ }^{\circ} \mathrm{C}$. Culture inoculum was prepared by harvesting cells during the late exponential growth phase (ca. $8 \mathrm{~h}$ ) in MRS broth. Cells were washed twice in $50 \mathrm{mM}$ sterile potassium phosphate buffer ( $\mathrm{pH}$ 7.0). The cell number of L. plantarum PU1 and Leuc. pseudomesenteroides DSM 20193 used to inoculate FL-BSG medium was ca. 7.0 Log colony-forming units (CFU)/mL. Both strains were cultivated in MRS as a control condition. Incubation was performed at $30^{\circ} \mathrm{C}$ for $24 \mathrm{~h}$. Biologically independent triplicates were performed for each condition. Kinetics of growth were determined by measuring the optical density at $620 \mathrm{~nm}$ (OD620) (UV1800 Spectophotometer, Shimazu, Japan) and through routine plate count. Plate count data were modelled according to the logistic equation available in grofit $\mathrm{R}$ package [16]. A is the maximum cell density reached by the culture at the stationary phase of growth (expressed as $\mathrm{CFU} / \mathrm{mL}$ ), $\mu$ max is the maximum growth rate $(\mathrm{CFU} / \mathrm{mL} \cdot \mathrm{h})$ and $\lambda$ is the length of the latency phase (expressed in $\mathrm{h}$ ). The $\mathrm{pH}$ was measured by a Crison pH-meter (model 507; Crison). 


\subsection{Phenotypic Microarray Analysis}

The phenotypic fingerprints of cells grown on FL-BSG medium and MRS were recorded using the OmniLog Phenotype MicroArray (PM) platform (Biolog, Hayward, CA, USA). Each PM assay was performed on two biological replicates, in accordance with the manufacturer's instructions. Briefly, cells at the late exponential (LE) growth (after ca. $14 \mathrm{~h}$ on FL-BSG medium and ca. $8 \mathrm{~h}$ on MRS) were collected, washed in sterile potassium phosphate buffer (50 mM, pH 7.0), and inoculated in PM1 and PM2 microplates, which account for 190 different carbon sources. Kinetic data from PM panels were automatically recorded by the OmniLog reader (Biolog) during incubation at $33^{\circ} \mathrm{C}$ for $48 \mathrm{~h}$. Generated longitudinal data were analyzed using the Micro4Food PM pipeline [17]. Briefly, blank subtraction was performed, and metabolic profiles were categorized as active and non-active. Metabolic signals were normalized per replicate and array [18]. After removal of common non-active profiles, metabolic parameters were computed using a free splines method and confidence intervals (CI) were determined through bootstrapping [16].

\subsection{Determination of Organic Acids and Sugars}

Organic acids and sugars were determined every four hours throughout the growth kinetics with a Dionex UltiMate 3000 (Thermo Fisher, Waltham, MA, USA) HPLC apparatus. Organic acids were analyzed by using an Aminex HPX-87H column (Biorad, Hercules, CA, USA) according to the method described by Zeppa et al. [19]. Sugars were determined by using a Spherisorb column (Waters, Millford, MA, USA) as described by Rizzello et al. [20].

The results were expressed as means of three biological replicates analyzed in triplicate \pm standard deviations.

\subsection{High-Performance Liquid Chromatography-Tandem Mass Spectrometry (HPLC-MS/MS) Analysis of Phenolic Compounds}

Cell suspensions of L. plantarum PU1 and Leuc. pseudomesenteroides DSM 20193 grown on FL-BSG media at $30^{\circ} \mathrm{C}$ for $24 \mathrm{~h}$ were harvested (after different periods of: $0,2,4,6,8$, $12,16,20$, and $24 \mathrm{~h}$ ), centrifuged (10,000 rpm for $5 \mathrm{~min}$ ), and the supernatant was filtered and stored at $-20{ }^{\circ} \mathrm{C}$ until further use. Separation and identification of phenolics was performed through liquid chromatography-tandem mass spectrometry (LC-MS/MS) analysis according to the method set up and validated by Tlais et al. [21] An ultra-high performance liquid chromatography (UHPLC) Dionex 3000 was coupled to an TSQ Quantum ${ }^{\mathrm{TM}}$ Access MAX Triple Quadrupole Mass Spectrometer (Thermo Fisher, Waltham, MA, USA) equipped with an electrospray source. A Waters Acquity HSS T3 column $1.8 \mu \mathrm{m}, 100 \mathrm{~mm} \times 2.1 \mathrm{~mm}$ (Milford, MA, USA) was used for the separation of phenolics. Elution was at $40{ }^{\circ} \mathrm{C}$, with a flow rate maintained at $0.4 \mathrm{~mL} / \mathrm{min}$. Eluent A consisted of $0.1 \%(v / v)$ formic acid in water, and eluent $B$ consisted of $0.1 \%(v / v)$ formic acid in acetonitrile. Samples were eluted with the following gradient: $0.0-3.0 \mathrm{~min}$ from $2 \%$ to $20 \% \mathrm{~B}, 3.0-4.3 \mathrm{~min}$ at $20 \% \mathrm{~B}, 4.3-9 \mathrm{~min}$ from $20 \%$ to $45 \% \mathrm{~B}, 9-11 \mathrm{~min}$ from $45 \%$ to $100 \% \mathrm{~B}, 11-13 \mathrm{~min}$ at $100 \%, 13-15 \mathrm{~min}$ from $100 \%$ to $5 \%$ B. Calibration curves were constructed using chemical standards, and phenolics concentrations were expressed as $\mathrm{mg} / \mathrm{L}$ of FL-BSG medium. Detection was performed in the multiple reaction monitoring (MRM) mode. Data acquisition was interfaced to a computer workstation running Xcalibur software version 4.1 (Thermo Fisher, Waltham, MA, USA). Chemical standards were used for phenolics identification by comparison of retention time and qualifier and quantifier ions. The results were expressed as means of three biological replicates analyzed in triplicate \pm standard deviations.

\subsection{RNA Isolation and Transcript Analysis by Quantitative Real-Time Polymerase Chain Reaction} (RT-PCR)

Total RNAs were obtained from $1 \mathrm{~mL}$ of L. plantarum PU1 and Leuc. pseudomesenteroides DSM 20193 cells respectively grown in FL-BSG and MRS media at $30^{\circ} \mathrm{C}$ until the LE phase of growth was reached after 14 and $8 \mathrm{~h}$, respectively. Samples (ca. $8 \log \mathrm{CFU} / \mathrm{mL}$ ) were centrifuged $\left(9000 \times \mathrm{g}\right.$ for $10 \mathrm{~min}$ at $\left.4{ }^{\circ} \mathrm{C}\right)$ and RNA isolation was performed with Stool 
Total RNA purification kit as recommended by the manufacturer (Norgen, Thorold, ON, Canada) with some modifications. Cells were lysed using $200 \mu \mathrm{L}$ of lysozyme $15 \mathrm{mg} / \mathrm{mL}$ and $20 \mu \mathrm{L}$ of Proteinase K (Qiagen, Hilden, Germany) for 45 min at $25^{\circ} \mathrm{C}$ under constant shaking (2000 rpm). Seven hundred $\mu \mathrm{L}$ of lysis buffer were added to the mixture and shaken vigorously. Five-hundred $\mu \mathrm{L}$ of propanol were used to precipitate the nucleic acids. Lysate was loaded into the column following the manufacturer's instructions. Total RNA was treated with RNase-free TurboTM DNase (Ambion, Austin, TX, USA). Quality and quantity control of RNA was obtained on agarose-gel electrophoresis and by NanoDrop ND-1000 spectrophotometer (Thermo Fisher, Waltham, MA, USA), respectively.

Total RNA was transcribed to cDNA using random hexamers priming and the Tetro cDNA synthesis kit according to the manufacturer's instructions (Bioline, London, UK). Primers for L. plantarum targeting pbg6, pbg4 and scrB genes and for Leuc. pseudomesenteroides amplifying $I N V, x y l A$ and pbg-like genes were used in this study. The specificity of the designed primer pairs was previously showed [22]. All reactions were set up in a QuantStudio 5 (Applied Biosystems, Germany) equipped with a 96 well reaction block. The reaction mixture $(20 \mu \mathrm{L})$ contained $10 \mu \mathrm{L}$ of TB Green ${ }^{\mathrm{TM}}$ Premix Ex Taq ${ }^{\mathrm{TM}}$ II (Tli RNaseH Plus) quantitative polymerase chain reaction (qPCR) master mix (Takara, Japan), $1 \mu \mathrm{L}$ cDNA sample, and appropriate primer concentration (Table 1). Assays were carried out in triplicate on three biological replicates. PCR required an initial denaturation at $95{ }^{\circ} \mathrm{C}$ for $30 \mathrm{~s}$, followed by a 40 -cycle amplification consisting of denaturation at $95^{\circ} \mathrm{C}$ for $5 \mathrm{~s}$, annealing for 34 and $30 \mathrm{~s}$ for Leuc. pseudomesenteroides DSM 20193 and L. plantarum PU1, respectively, and the extension was for 34 and $40 \mathrm{sec}$, respectively (Table 1). Fluorescence signals were normalized according to ROX reference dye levels. After the last cycle of each amplification, a melt curve analysis, with a temperature range from 60 to $95^{\circ} \mathrm{C}$ ramping at $1{ }^{\circ} \mathrm{C} / 5 \mathrm{~s}$, was performed to determine the product specificity. Gene expression data were normalized to levels of the $16 \mathrm{~S}$ rRNA housekeeping gene and analyzed using a comparative cycle threshold method $(\Delta \Delta C T)$. Levels of expression of genes were compared using the relative quantification method $[23,24]$. Real-time data are shown as the relative change compared to L. plantarum PU1 and Leuc. pseudomesenteroides DSM 20193 grown in MRS. Error bars show the standard deviations (SD) of the $\Delta \Delta C T$ value. For relative quantification, the value of $\Delta \mathrm{CT}$ for each sample was determined by calculating the difference between the value of $\mathrm{CT}$ of target genes and the value of $\mathrm{CT}$ of the $16 \mathrm{~S}$ rRNA housekeeping gene. Then, the value of $\Delta \Delta \mathrm{CT}$ for each sample was determined by subtracting the value of $\Delta \mathrm{CT}$ of the calibrator (reference sample) from the $\Delta \mathrm{CT}$ value for the sample. The normalized level of target gene expression was calculated by using the formula: $2>\Delta C T$. A gene was considered overexpressed when its RE level was higher than 2 [25].

Table 1. Parameters of the growth kinetic of Lactiplantibacillus plantarum PU1 and Leuconostoc pseudomesenteroides DSM 20193 strains during fermentation of Finnish brewers' spent grain (FL-BSG) and Rich De Man, Rogosa and Sharpe (MRS) media at $30{ }^{\circ} \mathrm{C}$ for $24 \mathrm{~h}$.

\begin{tabular}{|c|c|c|c|c|}
\hline \multirow{2}{*}{ Media $^{a}$} & \multirow{2}{*}{ Species/Strain } & \multicolumn{3}{|c|}{ Growth $^{b}$} \\
\hline & & A & $\mu \max$ & $\lambda$ \\
\hline \multirow{2}{*}{ FL-BSG } & Lactiplantibacillus plantarum PU1 & $8.19 \pm 0.03^{C}$ & $0.27 \pm 0.02^{C}$ & $4.03 \pm 0.17^{C}$ \\
\hline & Leuconostoc pseudomesenteroides DSM 20193 & $8.10 \pm 0.06^{\mathrm{D}}$ & $0.40 \pm 0.03^{C}$ & $3.30 \pm 0.08^{\mathrm{B}}$ \\
\hline \multirow{2}{*}{ MRS } & L. plantarum PU1 & $9.73 \pm 0.03^{\mathrm{A}}$ & $0.53 \pm 0.01^{\mathrm{B}}$ & $2.38 \pm 0.06^{\mathrm{A}}$ \\
\hline & Leuc. pseudomesenteroides DSM 20193 & $9.53 \pm 0.03^{B}$ & $0.62 \pm 0.01^{\mathrm{A}}$ & $1.47 \pm 0.06^{\mathrm{C}}$ \\
\hline
\end{tabular}

${ }^{a}$ For the manufacture of the media, see Materials and Methods. ${ }^{\mathrm{b}}$ Growth data were modelled according modelled according to the logistic equation available in grofit $\mathrm{R}$ package [16]. Parameters for growth: A, maximum absorbance reached by the culture at the stationary phase of growth $(\log \mathrm{CFU} / \mathrm{mL}) ; \mu \max$, maximum growth rate $(\log \mathrm{CFU} / \mathrm{mL} \cdot \mathrm{h}) ; \lambda$, length of the lag phase $(\mathrm{h})$. Means within the columns followed by different letters (A to D) are significantly different $(p<0.05)$. Shown are mean values \pm standard deviations for the three batches of each type of media, analyzed in duplicate. 


\subsection{Statistical Analysis}

Data were subjected to one-way or two-way analysis of variance (ANOVA), and pairwise comparison of treatment means was achieved by Tukey's procedure at a $p$ value of $<0.05$, using the Tukey-Krammer test through HSD.test function available in agricolae $\mathrm{R}$ package [26].

\section{Results}

\subsection{Microbial and Biochemical Characterization of Raw FL-BSG}

Total microbial cell density of FL-BSG sample was $2.97 \pm 0.14 \mathrm{Log}$ CFU/g. Enterobacteriaceae were $3.90 \pm 0.14 \mathrm{CFU} / \mathrm{g}$ whereas Enterococcus and Staphylococcus were not found in $10 \mathrm{~g}$ of sample. Other spoilage microbial species, such as Aeromonas, Pseudomonas and coliforms, as well as acetic acid bacteria, yeasts and moulds were not found. Anaerobic bacteria were mostly facultative anaerobic in FL-BSG. Calcium, phosphor, iron and magnesium were found in FL-BSG at $69.4 \pm 7.0,40.8 \pm 4.1,52.6 \pm 7.9$ and $53.3 \pm 5.4 \mathrm{mg} / 100 \mathrm{~g}$, respectively. Potassium, manganese, and sodium concentration was lower (ca. 2-20\%) compared to the other minerals assayed.

\subsection{Kinetics of Growth and Organic Acids Production during FL-BSG Fermentation}

Both strains grew under FL-BSG conditions showing a maximum cell density lower than 9.0 Log/CFU (Table 1). Leuc. pseudomesenteroides DSM 20193 had the highest maximum growth rate ( $\mu$ max) in FL-BSG. A longer lag phase $(\lambda)$ was found for L. plantarum PU1 compared to Leuc. pseudomesenteroides DSM 20193. As expected, when cultivated in the rich MRS medium, both bacteria showed an increase (ca. one and a half more log cycle) of the cell density compared to the cultivation in FL-BSG medium. The values of $\mu$ max and $\lambda$ calculated based on the data modelling growth were almost consistent with the final cell densities. The greatest decrease of $\mathrm{pH}$ was reached by L. plantarum PU1 (1.32 \pm 0.10$)$ in FLBSG medium, which had an initial pH of 6.65, followed by Leuc. pseudomesenteroides DSM $20193(1.02 \pm 0.06)$. Kinetics of organic acids production were determined throughout $24 \mathrm{~h}$ of growth in FL-BSG and MRS media (Figure 1), and the production rate was calculated as the slope of the linear regression for a time range. Lactic acid was always the major fermentation end-product. Both strains showed a single metabolic phase during FLBSG fermentation.
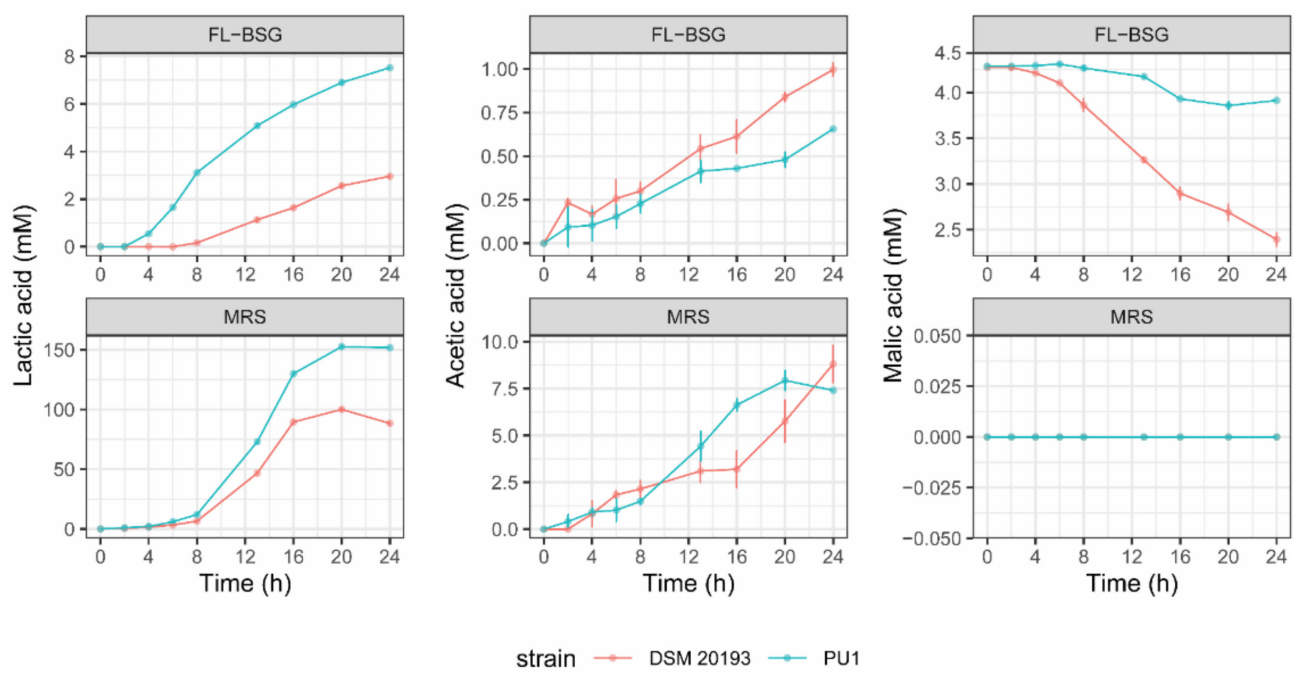

Figure 1. Organic acids production (mM) of Leuconostoc pseudomesenteroides DSM 20193 and Lactiplantibacillus plantarum PU1 during fermentation of Finnish brewers' spent grain (FL-BSG) and MRS at $30^{\circ} \mathrm{C}$ for $24 \mathrm{~h}$.

L. plantarum PU1 produced lactic acid from 2 up to $20 \mathrm{~h}$ with a rate of $0.41 \pm 0.01 \mathrm{mM} / \mathrm{h}$ with a final concentration (at $24 \mathrm{~h}$ ) of $7.52 \pm 0.18 \mathrm{mM}$. Leuc. pseudomesenteroides DSM 20193 
began to produce lactic acid after $8 \mathrm{~h}$ of growth in FL-BSG up to $20 \mathrm{~h}(2.56 \pm 0.07 \mathrm{mM})$ with a rate of $0.15 \pm 0.01 \mathrm{mM} / \mathrm{h}$, which corresponded to the beginning of the growth phase $\left(0.55 \pm 0.02 \mathrm{~h}^{-1}\right)$. Bacterial strains began to produce acetic acid from 2 up to $24 \mathrm{~h}$ of FL-BSG fermentation, which reached a final concentration of $1.00 \pm 0.03$ and $0.66 \pm 0.07 \mathrm{mM}$ for DSM 20193 and PU1, respectively. The rate of acetic acid production was slightly higher for DSM $20193(0.04 \pm 0.00 \mathrm{mM} / \mathrm{h})$ compared to PU1 $(0.03 \pm 0.00 \mathrm{mM} / \mathrm{h})$. Malic acid had an initial concentration of $4.27 \pm 0.02 \mathrm{mM}$ in FL-BSG and was mainly consumed by Leuc. pseudomesenteroides DSM 20193 after 6 h of growth $(0.09 \pm 0.01 \mathrm{mM} / \mathrm{h})$ with a final consumption of $1.88 \pm 0.08 \mathrm{mM}$ while PU1 showed a very low consumption with a rate of $0.02 \pm 0.01 \mathrm{mM} / \mathrm{h}$. When cultivated in MRS medium, the concentration of lactic and acetic acids markedly increased, but the ratio acetic - lactic acids was lower than FL-BSG. Due to the low levels of glucose, fructose and sucrose in FL-BSG media (Table S1), after $24 \mathrm{~h}$ of fermentation, these carbohydrates were below the limit of detection of the instrument.

\subsection{Phenotypic Profiles Adaptation to Brewers' Spent Grain Ecosystem}

A phenotypic screen for L. plantarum PU1 and Leuc. pseudomesenteroides DSM 20193 was performed in FL-BSG medium and compared to the MRS through the Phenotype MicroArray OmniLog PM technology (Biolog) (Figures 2 and 3). Cells were collected when the late exponential (LE) growth phase was reached and used to inoculate the PM plates. The range of phenotypes analysed included the transport, uptake, and catabolism of 190 carbon sources.

Principal component analysis of the area under the curve (AUC) computed from phenotype profile curves stratified the assayed conditions based on the genus and the culture medium (MRS and FL-BSG). Both strains showed a higher metabolic activity for a wider range of substrates when cultured in FL-BSG medium (global average AUC equal to $3024.8 \pm 2215.3 \mathrm{OL} \cdot \mathrm{h}$ ) compared to MRS (average AUC equal to $2410.9 \pm 2108.9 \mathrm{OL} \cdot \mathrm{h}$ ). The increase of activity was also reflected in higher metabolic rates and shorter lag phases for many compounds (Figure 3).

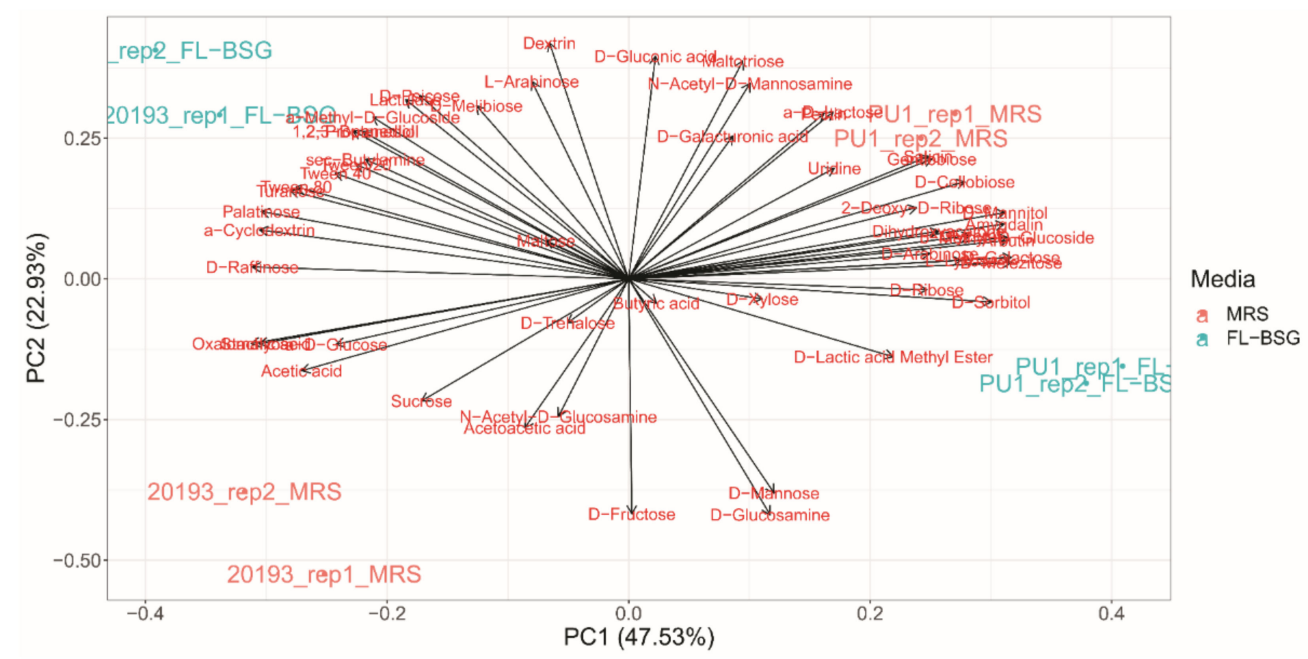

Figure 2. Principal component analysis (PCA) of the area under the curve (AUC) computed from phenotype microarray data for and Lactiplantibacillus plantarum PU1 and Leuconostoc. pseudomesenteroides DSM 20193 cultivated in Finnish brewers' spent grain (FL-BSG) and MRS at $30{ }^{\circ} \mathrm{C}$ for 14 and $8 \mathrm{~h}$. Loadings evidence substrate consumption across the PCA space.

Starch and sucrose metabolism compounds suffered the highest fluctuations when strains were swap from MRS to FL-BSG. The cultivation of Leuc. pseudomesenteroides DSM 20193 in FL-BSG stimulated the consumption of oligosaccharides (i.e., $\alpha$-cyclodexrin and pectin) when compared to PU1. Both strains increased their metabolism for D-cellobiose, which is linked to phospho- $\beta$-glucosidase activity found in these strains. Consequently, other $\beta$-glucosides such as gentiobiose, salicin and amygdalin were highly degraded under 
FL-BSG conditions. PU1 was the only strain able to degrade arbutin. The growth on FL-BSG medium stimulated the metabolism of maltose and maltotriose for both strains. Sucrose metabolism was stimulated when PU1 was cultured in BSG while DSM 20193 did not show a significant change when compared to MRS. However, the metabolism drift under FL-BSG of sucrose isomers was specie-dependent. The metabolism of D-threalose, turanose and D-melezitose were highly degraded by both strains, where DSM 20193 preferred turanose and the overall metabolism of melezitose was more intense in the PU1 strain. Contrastingly, the cultivation of DSM 20193 in BSG medium stimulated palatinose degradation but not for PU1, whose metabolism was found to be higher in MRS.

A)
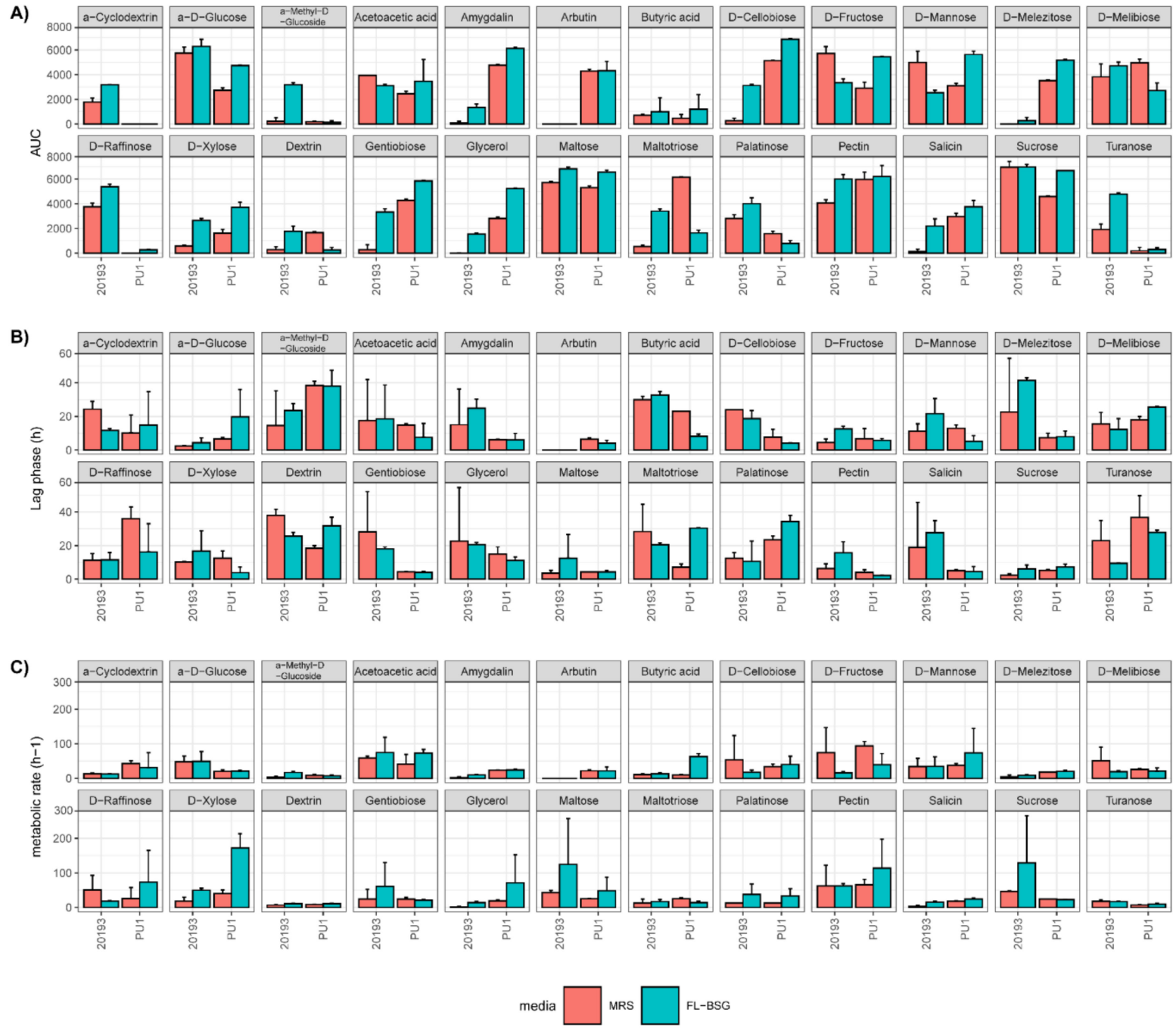

Figure 3. Metabolic parameters for selected substrates of Lactiplantibacillus plantarum PU1 and Leuconostoc pseudomesenteroides DSM 20193 (A) Area under the curve (AUC), (B) lag phase (h) and (C) metabolic tax $\left(\mathrm{h}^{-1}\right)$ cultured in Finnish brewers' spent grain (FL-BSG) and MRS during 14 and $8 \mathrm{~h}$ respectively, at $30^{\circ} \mathrm{C}$.

Fructose and mannose metabolism was more intense for L. plantarum PU1 when cultured on FL-BSG. Leuc. pseudomesenteroides DSM 20193 preferred mannitol while no significant $(p<0.05)$ differences were found for PU1 (Figure 3 ). Raffinose and its degradation product, melibiose, were also found to be highly consumed by Leuc. pseudomesenteroides DSM 20193 but no significant activity was found by L. plantarum PU1. Substrates involved in pentose and glucoronate interconversions pathway (e.g., xylose, D-galacturonic acid and pectin) were also highly metabolized in the BSG compared to the MRS condition by both strains. Glycerol was also degraded by both strains under FL-BSG. 


\subsection{Phenolic Profile Changes during BSG Fermentation}

We further investigated how the FL-BSG phenolic profile changed during $24 \mathrm{~h}$ of fermentation (Figure 4). Among 10 identified phenolic compounds, vanillin and syringic acid increased during the FL-BSG fermentation. The increase of vanillin occurred linearly during the first $6-8 \mathrm{~h}$ with a rate of $0.15 \pm 0.01$ and $0.13 \pm 0.01 \mathrm{~g} / \mathrm{L} \cdot \mathrm{h}$ for DSM 2013 and PU1. Analogously, DSM 2013 released syringic acid during the first $8 \mathrm{~h}$ with a rate of $0.10 \pm 0.01 \mathrm{~g} / \mathrm{L} \cdot \mathrm{h}$ while no consistent release of syringic acid was observed for L. plantarum PU1. A mild release of ferulic acid was found for DSM 20193 when cultured in FL-BSG after $4 \mathrm{~h}$ of incubation $(0.05 \pm 0.00 \mathrm{~g} / \mathrm{L} \cdot \mathrm{h})$ while the release of ferulic acid by L. plantarum PU1 occurred after $16 \mathrm{~h}$ of fermentation with a rate of $0.09 \pm 0.00 \mathrm{~g} / \mathrm{L} \cdot \mathrm{h}$.

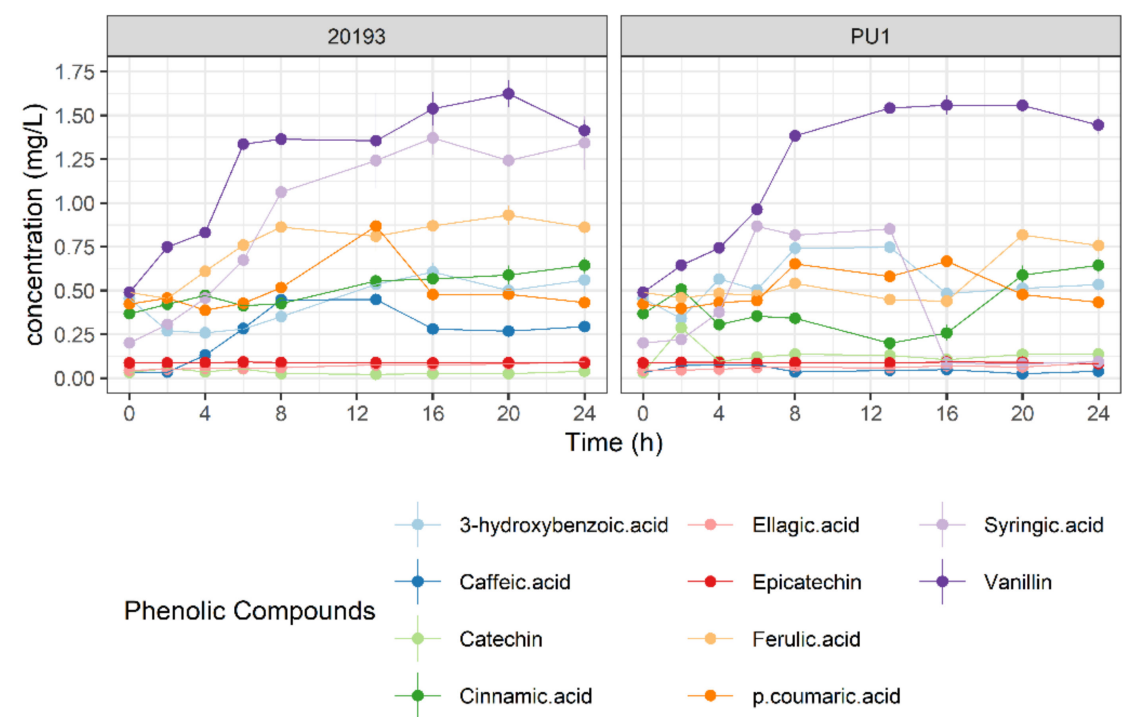

Figure 4. Profile evolution of phenolic compounds of Finnish brewers' spent grain (FL-BSG) fermented with Lactiplantibacillus plantarum PU1 and Leuconostoc pseudomesenteroides DSM 20193 for $24 \mathrm{~h}$ at $30^{\circ}$.

3.5. Gene Expression Coding for Galactose, Sucrose and Starch and Glucuronate Interconversions Pathways under Brewers' Spent Grain Conditions

Quantification of the expression of 6 genes involved in sucrose and its isomers metabolism (sucrose-6-phosphate hydrolases), and pentose and glucoronate interconversions pathway (xylose isomerase) was aimed to determine whether particular pathways are over-expressed in response to the BSG substrate (Table 2). Phospho- $\beta$-glucosidase activities were also targeted for putative enzymes involved in the degradation of cellobiose (pbg4 and pbg6 related genes) and other $\beta$-glucosides, such as gentiobiose and glycosylated forms of polyphenolic compounds ( $p b g 8$ gene).

L. plantarum PU1 over expressed ScrB ( $64.5 \pm 14.6$-fold), pbg4 (27.2 \pm 2.2 -fold) and $p b g 6$ (70.8 \pm 9.6-fold) genes during growth in FL-BSG conditions. By contrast, no overexpression was found for $p b g 8$ gene. Leuc. pseudomesenteroides DSM 20193 showed an overexpression of xylA (9.36 \pm 3.36 -fold) and INV (19.02 \pm 3.9-fold) genes after $14 \mathrm{~h}$ of FL-BSG fermentation. Pbg4-like gene, which encodes for a 6-phospho-beta-glucosidase was also differentially expressed $(7.03 \pm 2.68$-fold) under FL-BSG conditions. 
Table 2. Relative expression of selected genes of Leuconostoc pseudomesenteroides DSM 20193 and Lactiplantibacillus plantarum PU1 cultivated on Finnish brewers' spent grain (FL-BSG) until the late (after ca. $14 \mathrm{~h}$ ) exponential (LE) phase of growth at $30^{\circ} \mathrm{C}$ was reached. The calibrator conditions used were the same bacterial cultures grown in MRS until the LE phase of growth (after ca. $8 \mathrm{~h}$ ) at $30{ }^{\circ} \mathrm{C}$ was reached.

\begin{tabular}{cccc}
\hline Strain & Gene & Culture media & Fold Change \\
\hline & $p b g 4$ & FL-BSG & $27.18 \pm 2.17$ \\
Lactiplantibacillus & Mbg6 & MRS & $1.00 \pm 0.09$ \\
plantarum PU1 & FL-BSG & $70.76 \pm 9.62$ \\
& MRS & $1.01 \pm 0.15$ \\
& pbg-like & FL-BSG & $64.47 \pm 14.6$ \\
& & MRS & $1.41 \pm 1.01$ \\
\hline \multirow{2}{*}{ Leuconostoc } & FL-BSG & $7.03 \pm 2.68$ \\
Dseudomesenteroides & MRS & FL-BSG & $1.00 \pm 0.12$ \\
& & MRS & $9.36 \pm 3.36$ \\
& \multirow{2}{*}{ DylA } & FL-BSG & $1.01 \pm 0.18$ \\
& & MRS & $19.02 \pm 3.9$ \\
\end{tabular}

Data are the means of three biological replicates analyzed in triplicate \pm standard deviations.

\section{Discussion}

In the present study we provided insights into the metabolism of carbon sources and, particularly, of $\beta$-glycosides in L. plantarum and Leuc. pseudomesenteroides during brewers' spent grain (BSG) fermentation. Currently, BSG exploitation as a food ingredient is still limited due to its poor technological and sensory performance. High lignocellulosic content causes astringent flavors and woody texture properties. Effective reduction/modification of cellulose-derived and phenolic compounds in BSG might be achieved through an accurate selection of LAB starters with targeted metabolic activities [2,11]. L. plantarum and Leuc. pseudomesenteroides were used as model heterofermentative LAB because of their presence in plant niches and their role in bioprocessing of plant-based foods [2,27]. The production of dextrans by Leuc. pseudomesenteroides DSM 20193 and its positive impact upon plant-matrices technological and sensory properties was a promising metabolic trait [28-30]. The largest genome sizes $(1.93 \mathrm{Mb})$ of Leuc. pseudomesenteroides among $17 \mathrm{sub}-$ species of Leuconostoc genus suggests a wide panel of metabolic routes and fitness to plant ecosystems [31]. On the other hand, the paradigm of nomadic lifestyle is represented by $L$. plantarum since it did not undergo reductive evolution $[32,33]$. One example of its metabolic flexibility is the high redundant presence of phospho- $\beta$-glycosidase encoding genes [34,35]. Furthermore, the capability of L. plantarum PU1 to hydrolyze arabinoxylans present in aleurone BSG cell walls and to release peptides with high radical scavenging activity was previously demonstrated, suggesting its ability to improve the BSG technological and sensory features [12]. To the best of our knowledge, first this study showed a whole metabolic profiling, emphasizing phospho- $\beta$-glycosidase activities, from L. plantarum and Leuc. pseudomesenteroides under the BSG ecosystem compared to a standard laboratory medium. Despite the important role of LAB to exploit cereal by-products, few studies characterize in-depth LAB metabolism during lignocellulosic-like substrates. Our approach combined a whole-phenome characterization together with a set of metabolome analyses and differential gene expression to obtain insights into the metabolism of LAB related to the main constituents of BSG. The main minerals found were in agreement with previous studies, being calcium, magnesium and phosphorous the most abundant, where the total mineral content was slightly higher [36]. The growth of facultative bacteria and Enterococcus spp. on BSG might indicate a post-production proliferation [37].

Phenotype profiling unveiled the differentiation of metabolism of the strains under BSG and MRS standard condition, which reflected the effect of these contrasting environmental conditions. Metabolic performance was enhanced for a wider number of carbon sources under BSG conditions, evidencing the heterologous variety of complex carbohy- 
drates present in BSG [11,37]. This is also casted back in the higher ratio of acetic/lactic acid found for both strains under BSG compared to MRS and the consumption of malic acid to counteract stressful conditions.

Celluloses are the main constituent of BSG husk [11]. Although lactic acid bacteria have a limited cellulosic machinery, the L. plantarum WCFS1 genome harbors a putative endoglucanase ( $\left.l p \_3433\right)$ and eleven genes encoding for phospho- $\beta$-glycosidases activities [35,38]. Recently, we showed that phospho- $\beta$-glycosidases encoded in L. plantarum and Leuc. pseudomesenteroides DSM 20193 genomes diverged according to the specificity of the PTS complex they were associated, remarking their specificity for panel of $\beta$-glycosides substrates [22]. Phenotype profiling revealed an enhanced metabolism of gentiobiose and cellobiose under BSG conditions, which was reflected in shorter lag phases and higher metabolic rates. These preliminary findings were confirmed by gene expression analyses. L. plantarum PU1 significantly increased the expression of $p b g 6$ and pbg4 genes while Leuc. pseudomesenteroides DSM 20193 showed a higher fold change for a pbg-like gene. These genes are allocated in their respective operons along with cellobiose-specific PTS. The PTS systems associated to 6-phospho- $\beta$-glucosidases encoding genes showed in L. acidophilus a clear segregation depending on the induction by cellobiose or gentiobiose [39]. Notably, cellobiose and gentiobiose are composed of two glucose units only differing in the glycosidic linkage, $\beta-(1 \rightarrow 4)$ or $\beta-(1 \rightarrow 6)$ respectively. Our results highlight the importance of cellobiose metabolism linked to cellulosic substrates like BSG. We hypothesized that cellobiose is a pivotal carbon source for the growth and surveillance of L. plantarum and Leuc. pseudomesenteroides during BSG fermentation. Nonetheless, further investigation on the specificity of LAB $\beta$-glucosides PTS systems and 6-phospho- $\beta$-glucosidases is needed to establish their specificity towards other $\beta$-linked disaccharides such as gentiobiose $[40,41]$.

Because $\beta$-glycosidated phenols have a low bioactivity, LAB 6-phospho- $\beta$-glucosidases have demonstrated increasing nutritional properties of plant-based foods through the release of their respective aglycones [5,42]. Phenotyping revealed an increased consumption of salicin and amygdalin for both bacterial strains, and arbutin in the case of L. plantarum PU1, although no significant fold expression was found for the generic $\beta$-glycosideassociated pbg 8 gene for PU1 strain. Transcriptomic of L. plantarum cultured in fruit juices reported that $p b g 8$ was overexpressed after 30 days of maintenance and not during the growth phase [43]. Notably, a release of syringic acid and vanillin occurred during BSG fermentation with both bacterial strains. Most of the phenolic compounds found in BSG are related to lignin macromolecules, which are mainly constituted of vanillyl, syringyl and guaiacyl alcohols [44]. In plants, the monolignols synthesis is performed through the phenylpropanoid pathway where $\beta$-glycosilated conjugates are stored in the vacuole $[45,46]$. Hence, we hypothesized that $\beta$-glucosylated monolignols are degraded through 6-phospho- $\beta$-glucosidases during BSG fermentation and the resulting syringic acid is the result of specific benzyl alcohol dehydrogenase and aldehyde dehydrogenases [47,48]. Leuc. pseudomesenteroides DSM 20193 harbours only a phospho- $\beta$-glucosidases cellobioseassociated PTS system within the same operon suggesting a wider specificity of this transporter. In fact, previous studies demonstrated that generic $\beta$-glucoside PTS are essential for L. plantarum growth on fructooligosaccharides suggesting a wider specificity beyond $\beta$-glucosides $[49,50]$. Notably, degradation of $\beta$-fructosides caused an upregulation of $p \operatorname{bg} 10$ gene [51].

The presence of sucrose in BSG may results from residual endosperm starch [11,37]. We found an increase of metabolism for maltose, sucrose and/or its plant-derived isomer trehalose under BSG conditions. These findings correlated with the observed increase of fold-change for sucrose-6-phosphate hydrolase for both bacterial strains and the raw content of sucrose in the BSG. Furthermore, this enzymatic activity might also be involved in the degradation of anti-nutritional factors, such as raffinose, naturally present in BSG. This would explain the metabolic activity observed for this substrate by DSM 20193 under BSG conditions [37]. 
Arabinoxylans are the most abundant pentosans in BSG [37]. Phenotyping unveiled a high metabolic activity of xylose for both strains. In the case of Leuc. pseudomesenteroides DSM 20193, this finding agrees with the marked fold change of xylA gene. This strain harbors a $x y n B$ gene encoding for a 1,4- $\beta$-xylosidase, which enables it to cleave xylooligosaccharides [52]. Conversely, L. plantarum does not apparently encode for any gene for the degradation of xylosides. However, previous reports suggest a widespread presence of $c s c$ gene clusters encoding for cell surface protein complexes with ConA-like domains, which would be involved in binding and/or degradation of complex (plant-derived) oligoor poly-saccharides [53].

In this study, we provided a comprehensive view of the important role exerted by 6-phospho- $\beta$-glucosidases of Leuc. pesudomesenteroides DSM 20193 and L. plantarum PU1 as well the major metabolic routes undertaken during plant-based fermentation. Further challenges will consider a controlled characterization of $p b g$ expression correlated to the metabolism of $\beta$-glucosides with different aglycone moieties.

Supplementary Materials: The following are available online at 10.5281/zenodo.4295968, Table S1: Main chemical composition of the culture media. The data are the means of three independent experiments \pm standard deviation, analysed in duplicate. n.d., not detected.

Author Contributions: Conceptualization, R.D.C. and P.F.; methodology, A.D.R.; software, M.A.A.; validation, K.A., A.D.R.; formal analysis, M.A.-A.; investigation, M.A.-A.; resources, R.D.C.; data curation, M.A.-A.; writing-original draft preparation, M.A.-A.; writing-review and editing, R.D.C., P.F., M.G.; visualization, M.A.-A.; supervision, R.D.C.; project administration, M.G.; funding acquisition, R.D.C. All authors have read and agreed to the published version of the manuscript.

Funding: This research was funded by ERANET SUSFOOD-FUNBREW project.

Institutional Review Board Statement: Not applicable.

Informed Consent Statement: Not applicable.

Data Availability Statement: Not applicable.

Acknowledgments: We thank Carlo Rizzello from University of Bari A. Moro and Rossana Coda from University of Helsinki to provide the strains used in this study as well the substrate brewers' spent grain. We also thank Andrea Polo for following up mineral and mycotoxin determinations.

Conflicts of Interest: The authors declare no conflict of interest.

\section{References}

1. Salvetti, E.; O'Toole, P.W. The Genomic Basis of Lactobacilli as Health-Promoting Organisms. Microbiol. Spectr. 2017,5 , 49-71. [CrossRef]

2. Verni, M.; Rizzello, C.G.; Coda, R. Fermentation Biotechnology Applied to Cereal Industry By-Products: Nutritional and Functional Insights. Front. Nutr. 2019, 6, 1-13. [CrossRef] [PubMed]

3. Makarova, K.; Slesarev, A.; Wolf, Y.; Sorokin, A.; Mirkin, B.; Koonin, E.; Pavlov, A.; Pavlova, N.; Karamychev, V.; Polouchine, N.; et al. Comparative Genomics of the Lactic Acid Bacteria. Proc. Natl. Acad. Sci. USA 2006, 103, 15611-15616. [CrossRef] [PubMed]

4. Filannino, P.; Di Cagno, R.; Gobbetti, M. Metabolic and Functional Paths of Lactic Acid Bacteria in Plant Foods: Get out of the Labyrinth. Curr. Opin. Biotechnol. 2018, 49, 64-72. [CrossRef] [PubMed]

5. Michlmayr, H.; Kneifel, W. $\beta$-Glucosidase Activities of Lactic Acid Bacteria: Mechanisms, Impact on Fermented Food and Human Health. FEMS Microbiol. Lett. 2014, 352, 1-10. [CrossRef]

6. Riou, C.; Salmon, J.M.; Vallier, M.J.; Günata, Z.; Barre, P. Purification, Characterization, and Substrate Specificity of a Novel Highly Glucose-Tolerant Beta-Glucosidase from Aspergillus Oryzae. Appl. Environ. Microbiol. 1998, 64, 3607-3614. [CrossRef]

7. Son, S.-H.; Jeon, H.-L.; Yang, S.-J.; Sim, M.-H.; Kim, Y.-J.; Lee, N.-K.; Paik, H.-D. Probiotic Lactic Acid Bacteria Isolated from Traditional Korean Fermented Foods Based on $\beta$-Glucosidase Activity. Food Sci. Biotechnol. 2017, 27, 123-129. [CrossRef]

8. Michalska, K.; Li, H. GH1-Family 6-P-b-Glucosidases from Human Microbiome Lactic Acid Bacteria. Acta Crystallogr. D Biol. Crystallogr. 2013, 451-463. [CrossRef]

9. Postma, P.W.; Lengeler, J.W.; Jacobson, G.R. Phosphoenolpyruvate:Carbohydrate Phosphotransferase Systems of Bacteria. Microbiol. Rev. 1993, 57, 543-594. [CrossRef]

10. Mussatto, S.I. Brewer's Spent Grain: A Valuable Feedstock for Industrial Applications. J. Sci. Food Agric. 2014, 94, 1264-1275. [CrossRef] 
11. Lynch, K.M.; Steffen, E.J.; Arendt, E.K. Brewers' Spent Grain: A Review with an Emphasis on Food and Health. J. Inst. Brew. 2016, 122, 553-568. [CrossRef]

12. Verni, M.; Pontonio, E.; Krona, A.; Jacob, S.; Pinto, D.; Rinaldi, F.; Verardo, V.; Díaz-de-Cerio, E.; Coda, R.; Rizzello, C.G. Bioprocessing of Brewers' Spent Grain Enhances Its Antioxidant Activity: Characterization of Phenolic Compounds and Bioactive Peptides. Front. Microbiol. 2020, 11, 1-15. [CrossRef] [PubMed]

13. Zhao, J.; Dong, Z.; Li, J.; Chen, L.; Bai, Y.; Jia, Y.; Shao, T. Ensiling as Pretreatment of Rice Straw: The Effect of Hemicellulase and Lactobacillus Plantarum on Hemicellulose Degradation and Cellulose Conversion. Bioresour. Technol. 2018, 266, 158-165. [CrossRef] [PubMed]

14. Plessas, S.; Trantallidi, M.; Bekatorou, A.; Kanellaki, M.; Nigam, P.; Koutinas, A.A. Immobilization of Kefir and Lactobacillus Casei on Brewery Spent Grains for Use in Sourdough Wheat Bread Making. Food Chem. 2007, 105, 187-194. [CrossRef]

15. Wang, Y.; Sorvali, P.; Laitila, A.; Maina, N.H.; Coda, R.; Katina, K. Dextran Produced in Situ as a Tool to Improve the Quality of Wheat-Faba Bean Composite Bread. Food Hydrocoll. 2018, 84, 396-405. [CrossRef]

16. Kahm, M.; Hasenbrink, G.; Ludwig, J. Grofit: Fitting Biological Growth Curves with R. J. Stat. Softw. 2010, 33, 1. [CrossRef]

17. Acin-Albiac, M.; Filannino, P.; Gobbetti, M.; Di Cagno, R. Microbial High Throughput Phenomics: The Potential of an Irreplaceable Omics. Comput. Struct. Biotechnol. J. 2020, 18, 2290-2299. [CrossRef]

18. Vehkala, M.; Shubin, M.; Connor, T.R.; Thomson, N.R. Novel R Pipeline for Analyzing Biolog Phenotypic Microarray Data. PLoS ONE 2015, 10, e0118392. [CrossRef]

19. Zeppa, G.; Conterno, L.; Gerbi, V. Determination of Organic Acids, Sugars, Diacetyl, and Acetoin in Cheese by High-Performance Liquid Chromatography. J. Agric. Food Chem. 2001, 49, 2722-2726. [CrossRef]

20. Rizzello, C.G.; Nionelli, L.; Coda, R.; De Angelis, M.; Gobbetti, M. Effect of Sourdough Fermentation on Stabilisation, and Chemical and Nutritional Characteristics of Wheat Germ. Food Chem. 2010, 119, 1079-1089. [CrossRef]

21. Tlais, A.Z.A.; Da Ros, A.; Pasquale, F.; Vicentini, O.; Gobbetti, M.; Di Cagno, R. Biotechnological Re-Cycling of Apple by-Products: A Reservoir Model to Produce a Dietary Supplement Fortified with Biogenic Phenolic Compounds. Food Chem. 2021, 336, 127616. [CrossRef] [PubMed]

22. Acin-Albiac, M.; Filannino, P.; Coda, R.; Rizzello, C.G.; Gobbetti, M.; Di Cagno, R. The Metabolism of Lignocellulose-Derived Substrates Drives the Adaptation of Lactic Acid Bacteria during Fermentation of Brewers' Spent Grain: A Phenomics Evidence. Int. J. Food Microbiol. 2020, submitted.

23. Applied Biosystems. Real-Time PCR Handbook; ThermoFisher Scientific: Waltham, MA, USA, 2018; Volume 30.

24. Derveaux, S.; Vandesompele, J.; Hellemans, J. How to Do Successful Gene Expression Analysis Using Real-Time PCR. Methods 2010, 50, 227-230. [CrossRef] [PubMed]

25. Desroche, N.; Beltramo, C.; Guzzo, J. Determination of an Internal Control to Apply Reverse Transcription Quantitative PCR to Study Stress Response in the Lactic Acid Bacterium Oenococcus Oeni. J. Microbiol. Methods 2005, 60, 325-333. [CrossRef] [PubMed]

26. De Mendiburu, F. Package 'Agricolae' 2020. Available online: ftp://mirror.csclub.uwaterloo.ca/CRAN/web/packages/ agricolae/agricolae.pdf (accessed on 29 December 2020).

27. Jin, Q.; Liu, J.; Cassland, B.L.P.A.; Higgins, D.L. Detoxifying Pre-Treated Lignocellulose-Containing Materials 2018. U.S. Patent 20180273984, 17 July 2018.

28. Côté, G.L.; Skory, C.D. Cloning, Expression, and Characterization of an Insoluble Glucan-Producing Glucansucrase from Leuconostoc Mesenteroides NRRL B-1118. Appl. Microbiol. Biotechnol. 2012, 93, 2387-2394. [CrossRef] [PubMed]

29. Olvera, C.; Centeno-Leija, S.; López-Munguía, A. Structural and Functional Features of Fructansucrases Present in Leuconostoc Mesenteroides ATCC 8293. Antonie Leeuwenhoek 2007, 92, 11-20. [CrossRef]

30. Xu, Y.; Pitkänen, L.; Maina, N.H.; Coda, R.; Katina, K.; Tenkanen, M. Interactions between Fava Bean Protein and Dextrans Produced by Leuconostoc Pseudomesenteroides DSM 20193 and Weissella Cibaria Sj 1b. Carbohydr. Polym. 2018, 190, 315-323. [CrossRef]

31. Özcan, E.; Selvi, S.S.; Nikerel, E.; Teusink, B.; Toksoy Öner, E.; Çakır, T. A Genome-Scale Metabolic Network of the Aroma Bacterium Leuconostoc Mesenteroides Subsp. Cremoris. Appl. Microbiol. Biotechnol. 2019, 103, 3153-3165. [CrossRef]

32. Inglin, R.C.; Meile, L.; Stevens, M.J.A. Clustering of Pan- and Core-Genome of Lactobacillus Provides Novel Evolutionary Insights for Differentiation. BMC Genom. 2018, 19, 1-15. [CrossRef]

33. Duar, R.M.; Lin, X.B.; Zheng, J.; Martino, M.E.; Grenier, T.; Pérez-Muñoz, M.E.; Leulier, F.; Gänzle, M.; Walter, J. Lifestyles in Transition: Evolution and Natural History of the Genus Lactobacillus. FEMS Microbiol. Rev. 2017, 41, S27-S48. [CrossRef]

34. Kleerebezem, M.; Boekhorst, J.; van Kranenburg, R.; Molenaar, D.; Kuipers, O.P.; Leer, R.; Tarchini, R.; Peters, S.A.; Sandbrink, H.M.; Fiers, M.W.E.J.; et al. Complete Genome Sequence of Lactobacillus Plantarum WCFS1. Proc. Natl. Acad. Sci. USA 2003, 100, 1990-1995. [CrossRef] [PubMed]

35. Siezen, R.J.; Francke, C.; Renckens, B.; Boekhorst, J.; Wels, M.; Kleerebezem, M.; van Hijum, S.A.F.T. Complete Resequencing and Reannotation of the Lactobacillus Plantarum WCFS1 Genome. J. Bacteriol. 2012, 194, 195-196. [CrossRef] [PubMed]

36. Waters, D.M.; Jacob, F.; Titze, J.; Arendt, E.K.; Zannini, E. Fibre, Protein and Mineral Fortification of Wheat Bread through Milled and Fermented Brewer's Spent Grain Enrichment. Eur. Food Res. Technol. 2012, 235, 767-778. [CrossRef]

37. Robertson, J.A.; I'Anson, K.J.; Treimo, J.; Faulds, C.B.; Brocklehurst, T.F.; Eijsink, V.G.H.; Waldron, K.W. Profiling Brewers' Spent Grain for Composition and Microbial Ecology at the Site of Production. LWT Food Sci. Technol. 2010, 43, 890-896. [CrossRef] 
38. Zhao, S.S.; Wang, Y.P.; Yang, F.Y.; Wang, Y.; Zhang, H. Screening a Lactobacillus Plantarum Strain for Good Adaption in Alfalfa Ensiling and Demonstrating Its Improvement of Alfalfa Silage Quality. J. Appl. Microbiol. 2020. [CrossRef] [PubMed]

39. Andersen, J.M.; Barrangou, R.; Hachem, M.A.; Lahtinen, S.J.; Goh, Y.J.; Svensson, B.; Klaenhammer, T.R. Transcriptional Analysis of Prebiotic Uptake and Catabolism by Lactobacillus Acidophilus NCFM. PLoS ONE 2012, 7. [CrossRef] [PubMed]

40. Gänzle, M.G.; Follador, R. Metabolism of Oligosaccharides and Starch in Lactobacilli: A Review. Front. Microbiol. 2012, 3, 1-15. [CrossRef] [PubMed]

41. Ucar, R.A.; Pérez-Díaz, I.M.; Dean, L.L. Gentiobiose and Cellobiose Content in Fresh and Fermenting Cucumbers and Utilization of Such Disaccharides by Lactic Acid Bacteria in Fermented Cucumber Juice Medium. Food Sci. Nutr. 2020, 1-13. [CrossRef]

42. Ktenioudaki, A.; Alvarez-Jubete, L.; Smyth, T.J.; Kilcawley, K.; Rai, D.K.; Gallagher, E. Application of Bioprocessing Techniques (Sourdough Fermentation and Technological Aids) for Brewer's Spent Grain Breads. Food Res. Int. 2015, 73, 107-116. [CrossRef]

43. Filannino, P.; Di Cagno, R.; Crecchio, C.; De Virgilio, C.; De Angelis, M.; Gobbetti, M. Transcriptional Reprogramming and Phenotypic Switching Associated with the Adaptation of Lactobacillus Plantarum C2 to Plant Niches. Sci. Rep. 2016, 6, 27392. [CrossRef]

44. Rencoret, J.; Prinsen, P.; Gutiérrez, A.; Martinez, Á.T.; Del Rio, J.C. Isolation and Structural Characterization of the Milled Wood Lignin, Dioxane Lignin, and Cellulolytic Lignin Preparations from Brewer'S Spent Grain. J. Agric. Food Chem. 2015, 63, 603-613. [CrossRef] [PubMed]

45. Le Roy, J.; Huss, B.; Creach, A.; Hawkins, S.; Neutelings, G. Glycosylation Is a Major Regulator of Phenylpropanoid Availability and Biological Activity in Plants. Front. Plant Sci. 2016, 7. [CrossRef] [PubMed]

46. Dima, O.; Morreel, K.; Vanholme, B.; Kim, H.; Ralph, J.; Boerjana, W. Small Glycosylated Lignin Oligomers Are Stored in Arabidopsis Leaf Vacuoles. Plant Cell 2015, 27, 695-710. [CrossRef] [PubMed]

47. Rodríguez, H.; Antonio, J.; María, J.; De, B.; López, F.; Felipe, D.; Gómez-cordovés, C.; Miguel, J.; Muñoz, R. Food Phenolics and Lactic Acid Bacteria. Int. J. Food Microbiol. 2009, 132, 79-90. [CrossRef] [PubMed]

48. Kamimura, N.; Goto, T.; Takahashi, K.; Kasai, D.; Otsuka, Y.; Nakamura, M.; Katayama, Y.; Fukuda, M.; Masai, E. A Bacterial Aromatic Aldehyde Dehydrogenase Critical for the Efficient Catabolism of Syringaldehyde. Sci. Rep. 2017, 7, 44422. [CrossRef] [PubMed]

49. Chen, C.; Zhao, G.; Chen, W.; Guo, B. Metabolism of Fructooligosaccharides in Lactobacillus Plantarum ST-III via Differential Gene Transcription and Alteration of Cell Membrane Fluidity. Appl. Environ. Microbiol. 2015, 81, 7697-7707. [CrossRef] [PubMed]

50. Zúñiga, M.; Yebra, M.J.; Monedero, V. Complex Oligosaccharide Utilization Pathways in Lactobacillus. Curr. Issues Mol. Biol. 2020, 40, 49-80. [CrossRef]

51. Buntin, N.; Hongpattarakere, T.; Ritari, J.; Douillard, F.P.; Paulin, L.; Boeren, S.; Shetty, S.A.; de Vos, W.M. An Inducible Operon Is Involved in Inulin Utilization in Lactobacillus Plantarum Strains, as Revealed by Comparative Proteogenomics and Metabolic Profiling. Appl. Environ. Microbiol. 2017, 83, 1-13. [CrossRef]

52. Mazzoli, R.; Bosco, F.; Mizrahi, I.; Bayer, E.A.; Pessione, E. Towards Lactic Acid Bacteria-Based Biorefineries. Biotechnol. Adv. 2014, 32, 1216-1236. [CrossRef]

53. Siezen, R.; Boekhorst, J.; Muscariello, L.; Molenaar, D.; Renckens, B.; Kleerebezem, M. Lactobacillus Plantarum Gene Clusters Encoding Putative Cell-Surface Protein Complexes for Carbohydrate Utilization Are Conserved in Specific Gram-Positive Bacteria. BMC Genom. 2006, 7, 126. [CrossRef] 